\title{
DE "GRIPEZINHA" E "RESFRIADINHO" ÀS INCONTÁVEIS MORTES PELO CORONAVÍRUS: REFLEXÕES FILOSÓFICO-LINGUÍSTICAS SOBRE A RELAÇÃO SAÚDE-DOENÇA
}

\author{
FROM "GRIPEZINHA" AND "RESFRIADINHO" TO THE COUNTLESS DEATHS BY THE \\ CORONAVIRUS: PHILOSOPHICAL-LINGUISTIC REFLECTIONS ON THE HEALTH-DISEASE \\ RELATIONSHIP
}

Robson Figueiredo Brito*

\begin{abstract}
RESUMO
Este artigo aborda possíveis conexões entre a filosofia e a saúde no que diz respeito aos sentidos múltiplos que podemos flagrar do acontecimento da Pandemia da Covid-19 no planeta e no nosso País em 2020, levando em consideração a circulação de textos/discursos na sociedade. Ancoramo-nos em estudos filosóficos de Bakhtin, Volóchinov, na produção filosófica de investigação político-moral sobre as doenças no mundo moderno de Sontag e em estudos de Maingueneau, Mari, Possenti, Pêcheux, Orlandi e Foucault para refletirmos acerca da conectividade entre filosofia-saúde neste fenômeno deflagrado pela peste que nos afeta de maneira radical e nos faz pensar sobre o nosso lugar no mundo. Do ponto de vista metodológico, faremos uma leitura analítica do modo como os sujeitos interagem com a língua, o sistema/código, história e arte de rua para dizer e posicionar-se diante dessa doença. Escolhemos como dados linguístico-discursivos para serem postos em exame: $i$ ) dizeres do atual Presidente da República sobre a doença e ii) o vídeo-arte/pintura produzido para divulgar a obra do artista espanhol Pejac, em um hospital. A Filosofia, com seu arcabouço teóricometodológico, pode contribuir para desvelamento de vozes sociais que se contrapõem nessa crise, como o negacionismo científico versus a constatação da situação catastrófica causada pelo Coronavírus.
\end{abstract}

PALAVRAS-CHAVE: filosofia; saúde; Coronavírus; linguagens.

\section{ABSTRACT}

This paper addresses possible connections between philosophy and health with regard to the multiple meanings that we can catch from the Covid-19 Pandemic event on the planet and in our country in 2020, taking into account the circulation of texts/discourse in society. We anchor ourselves in philosophical studies by Bakhtin, Volóchinov, in the philosophical production of political-moral research on diseases in the modern world of Sontag and in studies by Maingeneau, Mari, Possenti, Pêcheux, Orlandi and Foucault to reflect on the connectivity between philosophy- health in this phenomenon triggered by the plague that affects us in a radical way and makes us think about our place in the world. From the methodological point of view, we will make an analytical reading of the way the subjects interact with the language, the system / code, the history and street art to tell and position themselves in the face of this disease. We chose as linguistic-discursive data to be examined: i) statements by the current President of the Republic about the disease and ii) the video-art/painting produced to publicize the work of the Spanish artist Pejac at a hospital. Philosophy with its theoretical-methodological framework can contribute to the unveiling of social voices that are opposed in this crisis, such as scientific denialism versus the observation of the catastrophic situation caused by the Coronavirus.

KEYWORDS: philosophy; health; Coronavirus; languages.

\footnotetext{
*Doutor em Letras. Professor do Departamento de Filosofia da PUC Minas. E-mail: robsonpucminas@gmail.com.
} 


\section{INTRODUÇÃO - O CAMINHO A SER TRILHADO}

"Mas, o que há, enfim, de tão perigoso no fato de as pessoas falarem e de seus discursos proliferarem indefinidamente? Onde, afinal, está o perigo?" (FOUCAULT, 2007, p. 8).

Este artigo aborda possíveis conexões entre a filosofia e a saúde no que diz respeito aos sentidos múltiplos que podemos flagrar do acontecimento ${ }^{1}$ da Pandemia da Covid-19 no planeta e, em nosso País, durante o ano de 2020, levando em consideração a circulação de textos/discursos, imagens de arte de rua e seus componentes no campo digital e midiático para compreender efeitos de sentido nas amarrações entre sujeito-linguagem-mundo nessa sofisticada relação.

Para este trabalho ancoramo-nos em fundamentações filosóficas de Bakhtin e Volóchinov, filósofos russos da Linguagem, e na investigação política e moral sobre as doenças no mundo moderno de Sontag e, também, nos estudos da língua(gem) de Maingueneau, Mari, Possenti, Pêcheux, Orlandi e estudos do discurso de Foucault, para refletirmos acerca da conectividade entre filosofia e saúde e, assim, analisarmos este fenômeno que atravessa de maneira radical o processo saúde-doença ${ }^{2}$ deflagrado pela Covid-19, com seus signos, significados e sentidos.

Do ponto de vista metodológico, faremos uma leitura analítica do modo como os sujeitos interagem com a língua, o sistema/código, história e arte de rua para dizer e posicionarse diante da doença causada pela Pandemia da Covid, que afeta as demandas humanas e existenciais associadas a todos os segmentos sociais no campo da saúde, porque permeia as

\footnotetext{
${ }^{1}$ Assinalamos aqui no início de nossa construção teórico-filosófica que acontecimento deve ser lido não apenas como um fato/fenômeno histórico em si, mas sob a égide da compreensão de Pêcheux (1990, p. 17) quando afirma que, ao considerarmos o discurso como estrutura, devemos "entrecruzar os caminhos do acontecimento, da estrutura e da tensão entre descrição e [...] no ponto de encontro de uma atualidade e de uma memória". E também em Bakhtin (2011), que argumenta acerca de nossa relação com a língua(gem) sob a perspectiva de que o dado puro não pode ser experienciado, e o dizer vem sempre orientado por um já-dito; uma resposta é atravessada pelo vozeamento social manifesto nos textos/discursos que estão entre nós, por isso a relação humana com a linguagem é sempre oblíqua, em diagonal.

${ }^{2}$ Estamos nos referindo ao processo saúde-doença sob dois enquadres: o primeiro tem relação com o modelo sistêmico da concepção do processo saúde-doença que, de acordo com Cruz (2012, p. 28), “[...] se configura como um processo dinâmico, complexo e multidimensional por englobar dimensões biológicas, psicológicas, socioculturais, econômicas, ambientais, políticas, enfim, pode-se identificar uma complexa inter-relação quando se trata de saúde e doença de uma pessoa, de um grupo social ou de sociedades". O segundo enquadre tem a ver com o modelo filosófico que, conforme Sontag (2007, p. 11, grifo da autora), “a DOENÇA É A ZONA NOTURNA DA VIDA, uma cidadania mais onerosa. Todos que nascem têm dupla cidadania, no reino dos sãos e no reino dos doentes. Apesar de todos preferirmos só usar o passaporte bom, mais cedo ou mais tarde nos vemos obrigados, pelo menos por um período, a nos identificarmos como cidadãos desse outro lugar. [...] Meu tema não é a doença física em si, mas os usos da doença como figura ou metáfora”.
} 
Artigo do dossiê: De "gripezinha" e "resfriadinho" às incontáveis mortes pelo coronavírus: reflexões filosófico-linguísticas sobre a relação saúde-doença

condições de vida, de trabalho e de enfrentamento de situações advindas desse fenômeno pandêmico carregadas de significados.

Essa composição de significados está inter-relacionada, por um lado, de acordo com Mari (2008), com a intencionalidade do sujeito na produção do seu processo comunicativo e, por outro lado, com o atravessamento de formações discursivas atreladas às formações ideológicas que afetam o posicionamento discursivo do sujeito (re) produtor da comunicação.

Com base nesse fundamento correspondente ao processo de significado construído pelo sujeito (re) produtor de sentidos, escolhemos como dados linguístico-discursivos para serem postos em análise neste artigo: I) dizeres do atual presidente da República sobre a doença causada pelo Coronavírus em um pronunciamento do dia 24 de março de 2020, em cadeia nacional, referindo-se a essa doença como "gripezinha" e II) o vídeo-arte/pintura produzido para divulgar a obra do artista espanhol Pejac — em uma rachadura do hospital de Vadecilla/Santander, Espanha - , cujo nome é "Distancia social", em recordação aos mortos pela Covid-19 e a todos os funcionários da saúde.

Uma pergunta se faz quando pensamos e refletimos acerca desse fenômeno que está ainda nos atravessando: o que a Pandemia da Covid-19 nos fez aprender? Esse $o$ quê nos propõe perscrutar o lugar da filosofia como fonte do conhecimento reflexivo e as possíveis significações discursivas produzidas por um chefe de Estado de um país como o Brasil e por um artista espanhol, que respondem semioticamente ${ }^{3}$ ao que essa doença nos causa, e que discursos proliferam desse fenômeno que está sendo a Pandemia.

Os dados linguístico-discursivos mencionados serão analisados a partir da fundamentação teórico-metodológica e filosófica dos estudos da linguagem de Bakhtin e Volóchinov e dos teóricos da Análise do Discurso Francesa, considerando a opacidade da língua (gem) e as múltiplas semioses contidas no vídeo-arte produzido para divulgar a pintura do artista espanhol como processos de produção de significação a respeito desse fenômeno que nos atingiu a todos: a Pandemia da Covid-19.

\footnotetext{
${ }^{3}$ Tomamos a noção de réplica na teoria de Bakhtin para fundamentar a resposta semiótica dada pelos atores sociais supracitados, porque todo dizer está e é orientado para uma resposta: "por trás de cada texto está o sistema da linguagem. A esse sistema corresponde no texto o que é repetido e reproduzido e tudo o que pode ser retido, tudo o que pode ser dado fora de tal texto (o dado)" (BAKHTIN, 2011, p. 272). "A atitude humana é um texto em potencial e pode ser compreendida (como atitude humana e não ação física) unicamente no contexto dialógico da própria época (como réplica, como posição semântica, como sistema de motivos)" (p. 310). "[...] para a compreensão do enunciado é ainda necessário, sobretudo estabelecer limites essenciais e precisos do enunciado. A alternância dos sujeitos do discurso. A capacidade de definir resposta. A responsividade de princípio de qualquer compreensão. Ademais, todo falante é por si mesmo um respondente em maior ou menor grau [...]” (p. 317).
} 


\section{FUNDAMENTOS TÉORICOS - NOÇÕES EM DISCUSSÃO:}

\section{A contribuição do Círculo de Bakhtin - noções filosófico-linguísticas}

\footnotetext{
"Ciências Humanas - ciências do espírito - ciências filológicas (o discurso é parte e ao mesmo tempo comum a todas elas)." (BAKHTIN, 2017, p. 66).
}

Neste tópico discutiremos com base no pensamento de filósofos russos que estudaram a relação entre a língua(gem), o sujeito, o discurso e a filosofia como uma forma não monológica do saber, isto é, em sua concepção dialógico-discursiva.

Bakhtin (2017) tece considerações a respeito do objeto de estudo e trabalho das ciências humanas: o ser falante e expressivo. O sujeito falante torna-se, sob o enquadre da expressividade, um ser produtor de sentidos e significados no mundo em que ele constrói um horizonte próprio como acontecimento e, dessa forma, não se organiza como um ser em prontidão, integralizado, terminado, com características da homogeneidade presente em outras teorias da língua(gem) e da subjetividade.

Esse horizonte humano, característico do falante, pode ser definido como uma metalinguagem que coincide com a complexidade dialética entre os sujeitos cognoscente e cognoscível, abrindo possibilidade para o entrecruzamento de duas consciências (a do eu e a do outro) para estabelecer o fracionamento de vozes/alternância dos sujeitos falantes em uma ou mais comunidades discursivas, explica o autor. Assim, o pensador russo afirma que, nesse entrecruzamento das consciências, o sujeito não pode ser percebido e estudado como coisa, porque tem o estatuto do ser que produz fala e está sempre aberto ao diálogo com e no mundo (BAKHTIN, 2017). Continuando sua reflexão, Bakhtin deixa entrever em suas ponderações sobre o modo como o sujeito se constitui em ser falante, produtor de palavras carregadas de réplicas internas e ou externas advindas do diálogo com as palavras de outrem; por essa razão, a Filosofia começa onde termina a cientificidade exata, uma vez que o seu objeto não é o de um ser monológico.

A Filosofia pode ser compreendida como uma metalinguagem de todas as ciências e também de modos do conhecimento e da consciência entre os sujeitos. O mundo torna-se um acontecimento no qual o sujeito falante é partícipe efetivo, porque atribui sentidos a ele sempre em mediação (BAKHTIN, 2017).

Com base em nossos estudos (BRITO, 2019), queremos ressaltar um elemento essencial para a compreensão do significado de mediatização da linguagem discutido por Bakhtin (2012) na sua obra Por uma filosofia do ato responsável, quando demarca que nossas experiências e 
Artigo do dossiê: De "gripezinha" e "resfriadinho" às incontáveis mortes pelo coronavírus: reflexões filosófico-linguísticas sobre a relação saúde-doença

vivências são atravessadas por significações, linguagens e produções de sentidos, e que o conhecimento de um objeto é sempre mediatizado e semiotizado, pois "o puro dado não pode ser realmente experimentado" (BAKHTIN, 2012, p. 50). Por conseguinte, na perspectiva de que não podemos, como seres humanos culturais e simbólicos, ter contato direto com a realidade, o autor argumenta: "quando eu experimento um objeto eu realizo alguma coisa em relação a ele: o objeto entra em relação com aquilo que é para-ser alcançado, cresce nisso, na minha relação com esse objeto" (BAKHTIN, 2012, p. 50).

Dessa forma, encontramos no pensamento bakhtiniano uma ponderação importante para respaldar teoricamente as experiências de produção de sentidos com e na linguagem: "todos os diversos campos da atividade humana estão ligados ao uso da linguagem. [...] o caráter e as formas desse uso [são] tão multiformes quanto os campos da atividade humana [...]" (BAKHTIN, 2016, p. 11).

Bakhtin argumenta que o emprego da língua acontece sob forma de enunciados, tanto orais quanto escritos, concretos e únicos, e são enunciados por integrantes dos mais diversos campos da atividade humana: "[...] cada enunciado particular é individual, mas cada campo de utilização da língua elabora seus tipos relativamente estáveis de enunciados, os quais denominamos gêneros do discurso" (BAKHTIN, 2016, p. 12).

Em nossos estudos (BRITO, 2016) mostramos que em Bakhtin (2011) encontramos uma explicação de como funcionam esses gêneros, porque são considerados como linhas de transmissão entre a história da sociedade e a história da linguagem. Por isso mesmo, Bakhtin dá ênfase ao tom produzido pelos gêneros primários, afirmando que são determinados pelos tipos de diálogo oral, íntimo, de salão, de círculo familiar, cotidiano, sociopolítico e filosófico, ponderando que tanto esses estilos individuais como os da língua fazem os gêneros do discurso e integram, assim, na chamada dinamicidade semiótica, que é assinalada por Faraco (2009, p. 58) como heteroglossia dialogizada, que é "o encontro sociocultural dessas vozes (vozes sociais) e a dinâmica que aí se estabelece [...]".

Nesse campo da comunicação discursiva, Bakhtin (2011) evidencia que os enunciados são carregados de tonalidades dialógicas e se comportam como um elo nessa cadeia de comunicação sócio-discursiva. E mais, o falante não é um sujeito adâmico, e o objeto de seu discurso é carregado de opiniões de interlocutores imediatos ou de pontos de vista e ou cosmovisões oriundas de determinadas esferas sócio-culturais ${ }^{4}$.

\footnotetext{
${ }^{4}$ O próprio Bakhtin (2011, p. 301) afirma que "cada gênero do discurso em cada campo da comunicação discursiva tem sua concepção típica de destinatário que determina como gênero". "[...] O enunciado em sua plenitude é
} 
Como o sujeito falante não é o primeiro a enunciar a palavra, em Bakhtin (2011, 2015) temos excertos que nos propiciam a compreensão de que o papel dos outros na constituição dos enunciados é fundamental e aguarda resposta destes: "o objeto do discurso do falante, seja qual for, não se torna pela primeira vez objeto do discurso em um dado enunciado". E, com isso, o objeto do discurso já foi qualificado por outros. Assim não há discurso sem confronto das consciências:

Cada enunciação concreta do sujeito de discurso é um ponto de aplicação tanto de forças centrípetas quanto de centrífugas. Nelas se cruzam os processos de centralização e descentralização, unificação e separação, a um basta não só a sua língua como materialização discursiva individual como também basta ao heterodiscurso, é seu participante ativo. (BAKHTIN, 2015, p. 42).

Não existe objeto de discurso que não seja dialógico. A transmissão da palavra de outrem é sempre parcial. A noção de diálogo se compõe como o espaço de tensão/conflito das vozes sociais que se tensionam, se entrecruzam, se completam, se polemizam, respondendo entre si em seu interior, carregadas de ideologia. Nessa perspectiva, o ouvinte tem uma posição ativa no processo de interação verbal, não sendo um duplicador da fala, mas está imerso no seu processo de produção, oferecendo a contrapalavra como uma expressão de atitude responsiva (BRITO, 2016).

Outro pensador russo que traz uma contribuição significativa e substancial para a nossa reflexão é Volóchinov (2019, p. 117), quando afirma que “obviamente, a palavra na vida não é autossuficiente. [...] a palavra é completada diretamente pela própria vida e não pode ser separada dela sem que o seu sentido seja perdido".

Ainda sobre a palavra, esse autor destaca que ela é parte integrante da comunicação ideológica e, por causa disso, atravessa todas as interações discursivas e o contato entre os sujeitos. Desse modo, afirma que "na palavra se realizam os inúmeros fios ideológicos que penetram em todas as áreas da comunicação social” (VOLÓCHINOV, 2019, p. 106).

A palavra se enuncia/manifesta como o indicador mais significativo e considerável de transformação social, sendo possível perceber que é capaz de marcar as modalidades de mudança por mais transitórias que sejam e se apresentem nos sistemas ideológicos estruturados, marcando assim a sua onipresença social ${ }^{5}$ (VOLÓCHINOV, 2017).

enformado como tal pelos elementos extralinguísticos (dialógicos), está ligado a outros enunciados. Esses elementos extralinguísticos (dialógicos) penetram o enunciado também por dentro" (p. 313).

${ }^{5}$ O próprio Volóchinov (2017) destaca que na relação da palavra com a ideologia e a consciência o importante é sua tessitura socioideológica e não a sua natureza sígnica. A palavra refrata e reflete na existência sua formação 
Artigo do dossiê: De "gripezinha" e "resfriadinho" às incontáveis mortes pelo coronavírus: reflexões filosófico-linguísticas sobre a relação saúde-doença

Em nossos estudos (BRITO, 2019) já mencionamos acerca da força interativa e da constituição enunciativa da palavra, pois desse modo podemos compreender, no cerne dos fundamentos construídos pelo Círculo de Bakhtin, que "o enunciado se forma entre dois indivíduos socialmente organizados e, na ausência de um interlocutor real, ele é ocupado, por assim dizer, pela imagem do representante médio daquele grupo social ao qual o falante pertence" (VOLÓCHINOV, 2017, p. 204).

Podemos apreender que um texto/discurso está povoado por vozes sociais que se entrecruzam continuamente, fazendo com que o sujeito responda sempre à cadeia de enunciados que o compõem numa luta com os recursos linguísticos: "[...] para um falante, a forma linguística é importante não como um sinal constante e invariável, mas como um signo sempre mutável e flexível" (VOLÓCHINOV, 2017, p. 173).

Prosseguindo em nossos estudos (BRITO, 2019), tomamos como referência o que Volóchinov (2017, p. 205) sustenta, ao afirmar que "o mundo interior e o pensamento de todo indivíduo possuem seu auditório social estável, e nesse ambiente se formam os seus argumentos interiores, motivos interiores e avaliações etc.”. O autor, ainda, defende que a palavra é apreendida pelo falante de um léxico social disponível, isto é, de um repertório de palavras, signos e significados sociais que compõem uma língua. Essa apreensão é formada de maneira individual, por enunciados concretos que são estabelecidos por relações socioistóricas.

Visitando a obra de Volóchinov (2019) A palavra na vida e a palavra na poesia, especificamente na parte "Para uma poética sociológica", encontramos um ponto crucial que sustenta a nossa reflexão filosófica sobre os modos de dizer dos sujeitos integrantes da comunicação discursiva, porque a palavra pronunciada por eles é considerada um acontecimento social:

\footnotetext{
Desse modo (já temos o direito de dizer isso), toda a palavra realmente pronunciada (ou escrita conscientemente) e não adormecida no léxico é a expressão e o produto da interação social entre os três: o falante (autor), o ouvinte (leitor) e aquele (ou aquilo) sobre quem (ou sobre o quê) eles falam (o personagem). (VOLÓCHINOV, 2019, p. 128 , grifos do autor).
}

Assim, podemos depreender que para Volóchinov (2019) a palavra é carregada de sentidos e significados sociais, e nesse processo da comunicação discursiva ela é determinada pela forma e pelo lugar da interação estabelecida entre os constituintes dessa comunicação.

social porque compreende e integra toda a práxis ideológica constituinte de todo processo dialético de uma sociedade.

Sapere aude - Belo Horizonte, v. 12 - n. 23, p. 66-86, Jan./Jun. 2021 - ISSN: 2177-6342 
Em síntese, os estudos de Bakhtin e Volóchinov aqui delineados por nós apresentaram aspectos significativos sobre a questão da palavra, do seu endereçamento intersubjetivo no ambiente do plurilinguismo ideologizado e da construção essencial da linguagem (dimensão social), porque posicionaram filosoficamente o homem enquanto falante, ser substancialmente socioistórico, que produz seus discursos nas trilhas da interação social.

\section{A CONTRIbUIÇÃo da ANÁliSE do DISCURSO FRANCESA (AD) - NOÇõeS FILOSÓFICO-LINGUÍSTICAS}

"Diante de qualquer fato, de qualquer objeto simbólico somos instados a interpretar, havendo uma injunção a interpretar.” (ORLANDI, 2015, p. 08).

Fundamentados nos estudos sobre a linguagem da Análise do Discurso Francesa, compreendemos que a língua(gem) é um elemento simbólico sem o qual o homem não cria o mundo. Com isso, "o trabalho simbólico do discurso está na base da produção da existência humana" (ORLANDI, 2015, p. 13).

Nesse campo teórico, a língua(gem) se constitui como meio necessário entre o real e a força motriz para o homem trabalhar com o simbólico e a produção de sentidos. A língua(gem) nessa situação não é transparente e se faz opaca, porque pode desvelar o atravessamento da ideologia no discurso e assim materializar relações em que se possa flagrar o trabalho da língua, do discurso e da ideologia na história, relacionando a linguagem à sua exterioridade.

Para a Análise do Discurso Francesa (AD), a relação do homem, sujeito de e na linguagem, é sempre parcial, carregada de atravessamentos ideológicos, e a língua se apresenta como um acontecimento. Em conformidade com Orlandi (2015) podemos destacar que: I) a língua tem autonomia relativa; II) os fenômenos são socioistóricos e demandam sentidos; III) o sujeito da língua(gem) é heterogêneo e descentrado e, por isso, não tem controle de como a língua o afeta.

Além disso, a Análise do Discurso Francesa tece considerações acerca de um entrecruzamento entre a história e a língua(gem) e propõe um novo tipo de compreensão da produção dos sentidos que acontecem na interação entre sujeito-discurso-ideologia. Esse acontecimento é sempre sujeito ao processo de interpretação que se processa por meio da construção de outras escutas do material linguístico-discursivo que se irrompe do lugar da falha apresentada por todo enunciado nesse jogo intrinsecamente exposto ao equívoco da língua (ORLANDI, 2012). 
Artigo do dossiê: De "gripezinha" e "resfriadinho" às incontáveis mortes pelo coronavírus: reflexões filosófico-linguísticas sobre a relação saúde-doença

Prosseguindo nossa reflexão sobre essa relação entre sujeito-língua-ideologia, marcadamente na história encontramos a noção de que é necessário pensar o processo da discursividade carregado pela energia viva dos sentidos como expressos em um dito, um dizer, um enunciado dentro da rede de significância da enunciação (MAINGUENEAU, 2008a). Assim é preciso, segundo Maingueneau (2008b), apreender o discurso como um sistema de regras que define a especificidade do processo de enunciação e também como ele é disposto em relação a outros discursos, constituindo a relação interdiscursiva que se faz na interação semântica entre os fios discursivos que determinam o dinamismo da significância e entrecruza toda a discursividade ${ }^{6}$.

Outra noção que destacamos, nesse campo teórico, é de cena de enunciação, que se constitui, de acordo com Maingueneau (2008a, p. 51), como uma cenografia em um momento da enunciação, ou seja, "o discurso implica certa situação de enunciação, um ethos, um código linguageiro através dos quais se configura um mundo que, em retorno, os valida por sua própria emergência". Essa tríade da cena de enunciação, conforme esse autor afirma, revela um movimento de representação e significação no e do discurso da própria enunciação que acontece como um investimento da diversidade em zonas e registro da língua(gem) e implica o processo de interação entre enunciador e coenunciador que, de certo modo, evidencia e enuncia modos de dizer dentro de um lugar enunciativo que gera sentido às práticas linguageiras humanas e aos discursos constituintes (MAINGUENEAU, 2008a).

Partindo do pressuposto de que não há discurso sem sujeito, não podemos deixar de mencionar que a noção de sujeito é muito cara para a $\mathrm{AD}$ e, por essa razão, buscamos ancorar em "O sujeito fora do arquivo", especialmente no aspecto em que Possenti (2009) explicita o trabalho do sujeito com o discurso da e na língua(gem), quando argumenta que nesse jogo interlocutivo o discurso pode ser tomado como um acontecimento e uma peça da estrutura enunciativa, e nessa rede de significância o sujeito se faz presente.

Para Possenti, o primeiro nome da tríade, presente na inter-relação do sujeito-discurso e língua, tem lastro socioistórico e por sua vez apresenta uma identidade singular, sendo integralmente atravessado pela história sem perder as circunstâncias e a pessoalidade. Assim, no trabalho com a língua(gem), o sujeito age porque acumula saberes em sua prática cultural e

\footnotetext{
${ }^{6}$ Assinalamos a noção de que "todo discurso, como toda cultura, é finito, na medida em que repousa sobre partilhas iniciais, mas essas partilhas não tomariam forma sobre um espaço semântico indiferenciado" (MAINGUENEAU, 2008b, p. 21).

${ }^{7}$ Nome do capítulo de autoria de Possenti (2009) em Os limites do discurso: ensaio sobre o discurso e sujeito, obra em que discute o trabalho do sujeito da e na língua (gem).
} 
histórica, mas é interpelado pelo discurso, e o seu modo de dizer passa pela estrutura da enunciação. Ao dizer, o sujeito materializa suas intenções e, não obstante, é crivado pelo inconsciente e pela ideologia. Em razão disso o discurso tem duas molas mestras que funcionam, por um lado, como um acontecimento e, por outro lado, como uma peça de uma estrutura carregada de significantes e significados afetando e atravessando o sujeito em seu dizer.

E, por fim, outra noção que merece destaque é o silêncio na e pela linguagem, porque nesse campo teórico pode ser considerado como um significante que se apresenta como um não dito desvelado no interior da língua(gem), como pondera Orlandi (2007), quando advoga que o silêncio não é complementar ao dito, ao discurso e à língua. Desse modo, o silêncio toma forma de agente garantidor do movimento dos sentidos e de seus efeitos no discurso enquanto acontecimento e peça da estrutura da enunciação.

Desse modo, sob o enquadre teórico-metodológico da $\mathrm{AD}$, o silêncio pode ser tomado como algo representável e, para essa autora, torna-se compreensível na rede de significância, uma vez que está inserido na abertura do processo de conhecimento dos modos de significar o ato discursivo. Em função disso, "o sujeito não adere às formações discursivas automaticamente e elas, por sua vez, não se apresentam como espaços maciços de sentido" (ORLANDI, 2007, p. 87).

Nesse enquadre da $\mathrm{AD}$, para Orlandi o silêncio significa, porque não fala e não se constitui como ausência de palavras, contudo evidencia na trama discursiva o seu aspecto fundador, tornando possível em sua política as cisões entre o dizer e o não dizer. As palavras vêm cheias de silêncio, desse jeito podem-se flagrar, a partir de observações discursivas, rupturas significativas na relação dos sentidos, como apresentaremos na análise de um dado semiótico selecionado para análise neste artigo, levando em conta como o silêncio se desvela na trama do acontecimento discursivo e enunciativo da Pandemia da Covid-19 e em suas representações significativas.

\section{FUNDAMENTOS METODOLÓGICOS - base para uma leitura analítica dos dados}

“[...] o sentido dos enunciados não está diretamente acessível ao analista. Para atingilos, deve-se recorrer a um aparato teórico. A relação entre dizer e sentido é indireta devido à opacidade da linguagem." (TFOUNI; PEREIRA, 2018, p. 128).

Embasados nos estudos sobre a língua(gem) na perspectiva da $\mathrm{AD}$ e a filosofia da 
Artigo do dossiê: De "gripezinha" e "resfriadinho" às incontáveis mortes pelo coronavírus: reflexões filosófico-linguísticas sobre a relação saúde-doença

linguagem do Círculo de Bakhtin, sabemos que a língua se constitui como prática social situada em contextos diversos e, por isso, não é apenas um signo e sim uma ação humana sobre o mundo.

À vista disso, ancoramo-nos na noção de que para ler um dado linguístico (modos de dizer e escrever) e um dado semiótico (modo de produzir arte) não podemos abrir mão de que o texto/discurso é carregado por vozes sociais, que a luta com os recursos linguísticos está carregada de memórias tanto históricas quando discursivas (GERALDI, 2002), e o estético, o jurídico e a arte são campos diferentes do social e sempre carregados de múltiplos sentidos. E esta última integra a comunicação social de um modo específico, porque revela a sua forma poética sociológica inserida em uma contemplação cocriativa (VOLÓCHINOV, 2019).

Sob o ponto de vista da AD, ler é poder flagrar efeitos de sentidos que fazem parte do processo do trabalho humano com e na linguagem, e com isso os sentidos são construídos na relação socioistórica em determinados jogos interlocutivos, pois "quando se lê, considera-se não apenas o que está dito, mas também o que está implícito, aquilo que não está dito e também está significando" (ORLANDI, 2012, p.13).

Para ler os dados selecionados para este artigo não perderemos de vista que os sentidos de um texto/discurso e de uma obra de arte são constituídos significativamente na relação com outros textos e produções semióticas produzidas no contexto das relações de poder em nossa sociedade atual, especificamente neste tempo de Pandemia.

A seleção do material linguístico e semiótico para este artigo levou em consideração: $a$ ) pronunciamentos do atual ocupante do cargo de chefe de Estado do Brasil, nas redes sociais, em relação ao processo de fazer circular que o coronavírus causaria nas pessoas apenas uma gripezinha (grifo nosso), ou seja, um mal-estar passageiro que com o tempo desapareceria e $b$ ) um vídeo-arte produzido a partir da obra de Pejac, artista de rua espanhol, quando faz uma pintura na fenda de uma parede no hospital de Vadecilla/Espanha, em memória aos mortos da Covid-19 e em reverência a todos os funcionários da Saúde que cuidam diuturnamente dos pacientes acometidos por essa doença.

Esses dados serão examinados por nós, considerando a opacidade da linguagem, a polissemia, a polifonia dos significantes, as cenas de enunciação e também pontos de silêncio evocados de modo indireto por esse material simbólico que abre brechas para depreendermos a indicialidade ${ }^{8}$ presente

\footnotetext{
${ }^{8}$ Sinalizamos que a metodologia de leitura para este dado está ancorada na ideia de que o conhecimento humano é construído de modo indireto e por meio do desvelamento de pistas, marcas tais quais nos sugerem Tfouni e Pereira (2018) em Análise indiciária: uma tipologia das singularidades, fazendo referência ao paradigma indiciário de Ginzburg, marcando o que faz o pesquisador de indícios na direção do conhecimento produzido pelos seres humanos em contextos históricos.
} 
tanto no texto/discurso do governante brasileiro quanto na obra do artista espanhol Pejac.

\section{DIZERES E SENTIDOS SOBRE A COVID-19 - TECENDO UMA LEITURA ANALÍTICA DOS DADOS}

\footnotetext{
"Qualquer doença importante cuja causalidade seja tenebrosa, e cujo tratamento seja ineficaz, tende a ser saturada de significação." (SONTAG, 2007, p. 53).
}

Amparados nos argumentos filosófico-linguísticos da AD, o nosso exame dos dados selecionados e descritos no tópico da metodologia vai em direção ao que Orlandi (2004, p. 09) elucida quando nos apresenta que "a interpretação está presente em toda e qualquer manifestação da linguagem. Não há sentido sem interpretação".

Sabemos que o homem, desde os primórdios da sociedade, sempre produziu significados e sentidos para interpretar as doenças; na contemporaneidade isso não poderia ser diferente, visto que este nome (doença) ganha, em diversos contextos, signos que vão possibilitar a nós, analistas do discurso, perscrutarmos as pistas linguístico-discursivas e semióticas para tal acontecimento.

O nosso exame dos dados começa com a análise da cena enunciativa flagrada na declaração sobre a possível chegada da Covid-19 ao Brasil, quando o Presidente da República faz um pronunciamento em 24 de março de 2020 à nação brasileira sobre o provável início da Pandemia:

\footnotetext{
Noventa por cento de nós não teremos qualquer manifestação, caso se contamine (sic), devemos sim é termos extrema preocupação em não transmitir o vírus para os outros, em especial aos nossos queridos pais e avós, respeitando as orientações do Ministério da Saúde. No meu caso particular, pelo meu histórico de atleta, caso fosse contaminado pelo vírus não precisaria me preocupar, nada sentiria ou seria quando muito acometido de uma gripezinha ou resfriadinho como bem disse aquele conhecido médico daquela conhecida televisão. (BRASIL, 2020, grifos nossos).
}

Nessa cena enunciativa produzida pelo atual ocupante do governo brasileiro, podemos flagrar, em seu modo de dizer, insígnias do primado do interdiscurso tal qual afirma Maingueneau (2008b): produção de enunciados de formações discursivas que se entrecruzam nos fios discursivos tal qual se apresenta em: "noventa por cento de nós não teremos qualquer manifestação, caso se contamine [...]" A afirmação que inicia esse enunciado pode ser percebida como uma pista linguístico-discursiva carregada de elementos utilizados em diagnósticos médicos por se tratar de uma referência a um dado estatístico que, por sua vez, remete a um 
Artigo do dossiê: De "gripezinha" e "resfriadinho" às incontáveis mortes pelo coronavírus: reflexões filosófico-linguísticas sobre a relação saúde-doença

dado epidemiológico 9 .

Além disso, ainda nessa cena enunciativa nota-se outra pista linguístico-discursiva no modo de dizer do presidente, quando afirma que "devemos sim é termos extrema preocupação em não transmitir o vírus para os outros, em especial aos nossos queridos pais e avós"; nesse momento faz alusão a outro aspecto presente no discurso médico - citação de grupo de risco ${ }^{10}$. E, ao final, alude à questão do respeito ao órgão máximo de saúde no País: “[...] respeitando as orientações do Ministério da Saúde".

Esse modo de dizer enunciado pelo governante brasileiro, que vem entremeado pelo interdiscurso e está fazendo referência ao discurso médico, pode ser um indicador de uma estratégia reveladora de precisão, embasamento, credibilidade a ser passada sob a batuta da certeza, respaldada nessa formação discursiva (discurso médico e seus avatares) presente nessa encenação de discurso político (gênero de pronunciamento à nação) para demonstrar a crença de poder administrar uma possível crise advinda por uma onda desse vírus (o coronavírus) que poderia causar mal à nação, espalhando certo pânico entre brasileiros e brasileiras, mas que estaria sob controle.

Isso pode ser observado em outro trecho, quando o ocupante do lugar de presidente do Brasil faz referência a si em: "no meu caso particular, pelo meu histórico de atleta, caso fosse contaminado pelo vírus não precisaria me preocupar, nada sentiria ou seria quando muito acometido de uma gripezinha ou resfriadinho, como bem disse aquele conhecido médico daquela conhecida televisão" (grifos nossos).

Alguém como eu, que tenho força física, e estou preparado para enfrentar corporalmente a doença posso inclusive minimizá-la. Isso pode ser notado por meio do emprego dos sufixos zinha e -inho para referir-se (avaliativamente) aos sintomas causados por essa doença. Esse modo de dizer pode denotar uma possível expressão de desqualificação do efeito maléfico do Coronavírus, na utilização do diminuitivo (sufixo -zinha e -inho) que acompanha várias expressões formadas no português brasileiro falado, e que em determinados contextos socioistóricos quando empregadas não servem apenas para designar expressões de tamanho, mas podem expressar diversas nuances, respectivamente, modo, intenção, ou mesmo, e muitas

\footnotetext{
${ }^{9}$ Fazemos referência a esses dados como oriundos da Epidemiologia, ciência que faz "o estudo dos fatores que determinam a frequência e a distribuição das doenças nas coletividades humanas" conforme evidencia Montilla (2008, p. 134).

${ }^{10}$ De acordo com a Organização Pan-americana de Saúde (OPAS) (2020a), são considerados grupo de risco para agravamento da Covid-19 os portadores de doenças crônicas, como diabetes e hipertensão, asma, doença pulmonar obstrutiva crônica, e indivíduos fumantes (que fazem uso de tabaco incluindo narguilé), acima de sessenta anos, gestantes, puérperas e crianças menores de cinco anos.
} 
vezes, desprezo, depreciação: pensar ligeirinho, cantar baixinho, ficar bonzinho, aquela coisinha.

No caso do dizer do presidente, podemos flagrar no uso de gripezinha e resfriadinho certa depreciação dos sintomas da doença causada pelo coronavírus e também um ataque ao trabalho de Dr. Dráuzio Varela (“aquele conhecido médico") que nacionalmente passa, a partir de seus conhecimentos científicos, informações sobre doenças e os cuidados que a população precisa tomar.

Esse modo de dizer denota certo menosprezo pela contaminação e pela gravidade dos sintomas causados pela Covid-19 e pode ser flagrado também sob a perspectiva de um não dito subjacente a esse dizer enunciado em tom chistoso e pode sinalizar um mecanismo de negação da realidade de contágio.

Ao produzir esse dizer de pouco caso em relação aos sintomas da doença que chega ao País, o enunciador toma para si a força de atleta (mesmo não sendo mais) e, especialmente, porque tem mais de sessenta anos e acredita estar supostamente assegurado pelo seu histórico de atleta como uma medida de defesa ao contágio da SARS Cov 2. Nesse jogo enunciativo e interlocutivo expresso nesse modo de dizer, que metaforiza a força atlética e o que pode propiciar a um sujeito em termos de condicionamento físico, de bem-estar e de proteção/defesa, podemos identificar uma crença um pouco ilusória do enunciador: se comigo acontecer a contaminação, não preciso me preocupar, porque tenho histórico de atleta, então não há motivo para alarme ou alarde diante dessa gripezinha ou desse resfriadinho.

A produção dessa crença de não contaminação do coronavírus pelo interlocutor pode ser explicada na afirmação de Possenti $(2009$, p. 81) de que “o falante sabe (integralmente?) o que está dizendo e ilude-se (integralmente?) se pensar que sabe o que diz (ou só diz o que quer) [...]". Esse enunciador constrói a crença de não contaminação do vírus da Covid-19 devido a seu histórico atlético baseado em um dizer que pode refratar o seguinte: já que sou a fonte do meu dizer e acredito deter também o sentido/conhecimento das palavras que pronuncio para o povo brasileiro, essa força está comigo e vai me proteger do contágio. Ao dizer isso, o ocupante do cargo de Presidente pode evidenciar, nesse ponto de seu discurso, um atravessamento de uma ideologia e de ações de modo consciente ou não do processo de negação do contágio e transmissão da doença em questão, que se inscreve na Formação Discursiva do negacionismo da ciência, porque faz menção a um médico infectologista respeitado no País e que atua como consultor de um programa de televisão.

Ele faz essa referência ao profissional da medicina de modo jocoso, provocativo, quando 
Artigo do dossiê: De "gripezinha" e "resfriadinho" às incontáveis mortes pelo coronavírus: reflexões filosófico-linguísticas sobre a relação saúde-doença

utiliza de expressões como "aquele conhecido médico daquela conhecida televisão" (grifos nossos), e com isso podemos flagrar nesse gesto de referir por meio dessa pista linguísticodiscursiva o uso de dêiticos que irão desvelar determinada cenografia de uma formação discursiva, tal qual Maingueneau (2008b, p. 42) argumenta quando sinaliza que "uma formação discursiva, na realidade, só pode enunciar de forma válida se puder inscrever sua alocução nos vestígios de uma outra dêixis, cuja história ela institui ou 'capta' a seu favor".

O emprego do dêitico aquele junto ao adjetivo masculino conhecido para, "sem dar nome", explicitar sua referenciação de modo a indicar que, enquanto ouvintes do pronunciamento, sabemos de quem se trata, e isso se faz em relação ao uso do dêitico daquela acompanhado do adjetivo feminino conhecida para referir-se à emissora de televisão famigerada, a TV Globo, ou seja, não precisamos dar tanto valor a isso.

Esse gesto do dizer, além de ser uma provocação, pode revelar um embate de poder dele, presidente, em direção à emissora de TV no tratamento da chegada da Covid-19 ao País e, também, uma crítica ao exagero em relação aos malefícios do coronavírus e suas complicações críticas que foram neste pronunciamento desqualificadas e interpretadas, de certo modo ilusório, por ele, o mandatário do País, como um mal menor, negando, assim, o poder da ciência para tratar essa doença.

Enfim, esses modos de dizer do ocupante da presidência do Brasil podem ser examinados sob o enquadre dos estudos da linguagem de Bakhtin (Análise Dialógica do Discurso) e, possivelmente, revelam por meio das pistas linguístico-discursivas do emprego dos diminutivos -zinha e -inho (sufixos) e aquele e daquela (pronomes dêiticos discursivos) índices das vozes da negação da ciência e da desqualificação dos sintomas causados pelo vírus da Covid-19. São reveladores de que estamos lidando com uma doencinha e que não é preciso, por conseguinte, levá-la tão a sério, ou seja, o seu mal-estar é dimensionado de modo insignificante.

As vozes sociais que atravessam os modos de dizer do enunciatário podem indicar na rede dialógica de produção de sentido um determinado ponto de confronto com outra voz social que expressa uma palavra alheia que vem da Organização Mundial de Saúde acerca dessa doença: "O diretor-geral da Organização Mundial da Saúde (OMS), Tedros Adhanom Ghebreyesus, anunciou nesta quarta-feira (11), em Genebra, na Suíça, que a COVID-19, doença causada pelo novo coronavírus, é agora caracterizada como uma pandemia." (ORGANIZAÇÃO PAN-AMERICANA DE SAÚDE, 2020b).

A voz social que vem desse órgão mostra que, cientificamente, a Covid-19 não é um 
mal-estar menor e sim uma grande pandemia e alerta que para as Américas a transmissão será comunitária e em massa. Além disso, faz um pedido para que os governos empreguem três verbos para combater a doença: detectar, proteger, tratar. Desse modo, percebemos que por meio desse pedido há também uma voz de cuidado que, junto à ciência, expressa: "vamos cuidar uns dos outros, porque precisamos uns dos outros" (ORGANIZAÇÃO PAN-AMERICANA DE SAÚDE, 2020b), deixando entrever outro aspecto que contraria a voz enunciada pelo presidente brasileiro: não cuidar apenas dos idosos e de quem é de grupo de risco. O cuidado e a prevenção são para todos nós seres humanos, passíveis de sermos contaminados. A OMS, com essa voz, dá o devido tamanho que a doença e a Pandemia da Covid-19 têm para o mundo e para o nosso País.

No outro lado do mundo, na Espanha, o artista de rua Pejac produz uma obra de arte (pintura de rua) na rachadura de uma parede do hospital de Vadecilla (Espanha) em recordação aos mortos pela Covid-19 e em homenagem a todos os funcionários da Saúde.

Para o nosso exame, tomamos um vídeo em que essa pintura se encontra, e o que nos chama a atenção é que durante a projeção e a aproximação da câmera em direção à rachadura, cada vez mais que há uma aproximação com essa obra, notamos, num primeiro plano, pontos pretos que, depois, vão-se transformando em pessoas.

O que podemos flagrar desse trabalho artístico, enquanto analistas do discurso, é que nessa produção digital (vídeo-arte) a primeira pista que se desvela é a do silêncio, porque vamos considerar o que está implícito, ou seja, a significância do sem som como um modo que toma forma de agente garantidor do movimento dos sentidos e de seus efeitos no discurso enquanto acontecimento e peça da estrutura da enunciação.

Essa forma de silêncio ${ }^{11}$, no vídeo, pode ser percebida, em princípio, quando o que vemos é uma brecha, uma fenda cheia de pontos pretos (rastros de tinta) que podem demonstrar algo nebuloso, sem sentido, "apenas" uma abertura na parede. Temos que recordar que esse buraco na parede está em uma construção de um edifício hospitalar, o Hospital de Vadecilla, que está funcionando como referência no tratamento de pacientes com Covid-19. A partir disso, depreendemos que essa imagem nebulosa (rachadura e rastro de tinta) pode significar o que a Pandemia nos causou no começo: incerteza, algo enigmático que ainda se apresentava

\footnotetext{
${ }^{11}$ Referimo-nos aqui à forma de silêncio como pondera Orlandi (2007, p. 17): “O funcionamento do silêncio atesta o movimento do discurso que faz a contradição entre o ‘um' e o 'múltiplo', o mesmo e o diferente, entre a paráfrase e a polissemia." E também a outro elemento importante, que no silêncio o analista do discurso pode "observar a construção do imaginário necessário na produção de sentidos" (p. 18).
} 
Artigo do dossiê: De "gripezinha" e "resfriadinho" às incontáveis mortes pelo coronavírus: reflexões filosófico-linguísticas sobre a relação saúde-doença

misterioso a todos nós.

Com a aproximação da lente da câmera, os pontos pretos de tinta começam a ganhar forma e tem-se a impressão de que da rachadura saem pessoas que estão em movimento, caminhando. O nosso olhar fica atento com o que se vai descortinando, porque novamente, em silêncio, surgem na pintura os seres humanos que foram afetados pelo coronavírus e perderam a vida para essa doença. O que podemos flagrar com essa imagem que vai desvendando desses pontos negros as formas humanas é que essa doença mata, é letal, não é uma gripezinha e ou um resfriadinho e sim algo que se espalha com uma velocidade muito grande e nos deixa perplexos.

$\mathrm{O}$ artista Pejac, em silêncio, significa e faz um movimento e um trabalho de registro para marcar os inumeráveis, isto é, aquelas pessoas que morreram vítimas da Covid-19, sem negar o seu efeito deletério. Dessa maneira, a arte marca na parede de um hospital, para quem passar e olhar, que ali naquele lugar as pessoas foram e estão sendo cuidadas por profissionais da saúde. Pode-se afirmar que isso é uma ode ao trabalho da ciência que acompanha e cuida das pessoas, mesmo que a doença que as acomete ainda não tenha cura.

Ao tomar posição de registro das vítimas e homenagear os profissionais de saúde que delas cuidaram e cuidam neste Hospital de Vadecilla, Pejac, como artista de rua, mostra, tal qual a OMS nos apresentou, que os sintomas da doença não são coisas passageiras, e também que um corpo atlético talvez não seja capaz, por sua força, de superar e ou vencer. No mundo já morreram cerca de três milhões, na Espanha mais de sessenta mil e no Brasil mais de trezentas mil pessoas vítimas dessa doença, e nesse grupo não estão somente idosos e sim crianças, jovens, adultos e idosos. O alerta de Pejac desencadeia um ponto que os nossos olhos podem e devem alcançar: a Pandemia é letal, faz vítimas.

\section{CONSIDERAÇÕES FINAIS}

“O sujeito não adere às formações discursivas automaticamente e elas, por sua vez, não se apresentam como espaços maciços de sentido.” (ORLANDI, 2007, p. 87).

Vivenciamos e sabemos que estamos mergulhados em uma crise de todas as ordens: social, econômica, política e sanitária sem precedentes nestes tempos de Pandemia da Covid19. Nunca fomos tão desafiados a pensar sobre o nosso lugar de seres no mundo e nas formas de lidar com o desconhecido que a peste nos trouxe.

A Filosofia, com seu arcabouço teórico-metodológico de nos fazer enxergar ou pelo 
menos nos ajudar a flagrar fragmentos do real, pode contribuir efetivamente com o desvelamento de vozes sociais que se contrapõem neste momento de crise como, por exemplo, o negacionismo científico versus a constatação da situação catastrófica causada pelo Coronavírus no mundo a partir de março de 2020.

Se, por um lado, temos a posição discursiva e enunciativa da maior autoridade ocupante da chefia do Estado Brasileiro que em seu modo de dizer revela por meio de marcas linguísticodiscursivas de diminuição, desqualificação da doença causada pelo coronavírus e seus sintomas sobre as pessoas projetando-a como um mal menor, temos, por outro lado, um artista de rua, Pejac, que com sua arte e seu pincel marca e registra no espaço urbano a sua leitura, em silêncio, de como a Covid-19 é letal, e insere na realidade, por meio de uma fenda na parede de uma instituição hospitalar, o quanto nós, pessoas que estamos imersos nessa crise, não podemos fechar os olhos para as vidas que foram ceifadas pelo efeito do vírus dessa doença.

Além disso, Pejac, ainda com o seu registro artístico, põe em cena para quem quiser ver que sua arte está numa parede entreaberta de um hospital que trata pacientes acometidos em estado grave pelo coronavírus. Ao deixar o seu rastro de pintor-observador-leitor comprometido com o seu ato de fazer arte, no silêncio presta uma homenagem aos profissionais de saúde que estão na linha de frente do cuidado, combatendo essa doença.

Enquanto isso, no Brasil, o pronunciamento do presidente da República nos aponta, como pesquisadores da linguagem e da filosofia, certa noção de um apagamento desastroso desse mal-estar que nos assola. Em seu dizer, o presidente também deixa entrever que um corpo atlético (são) não é susceptível de acometer-se com os possíveis estragos da Covid-19; essa ideia de não deixar-se contaminar por causa da boa saúde e do bem-estar causado pelo fato de ser forte, ou seja, de que ser atleta e seu histórico funcionariam como capa protetora que evitaria a ação de infecção do vírus: “[...] pelo meu histórico de atleta, caso fosse contaminado pelo vírus não precisaria me preocupar nada sentiria ou seria quando muito acometido de uma gripezinha”. Esse dito pode funcionar, tal qual o seu modo de enunciar, como algo apenas do campo da denegação inserida em uma formação discursiva do individualismo. Esse enunciado vai na contramão do que a realidade de causa-mortis na Pandemia da Covid-19 nos revela: bebês, crianças, adolescentes, jovens e atletas ou não atletas têm morrido não por causa da gripezinha e sim em decorrência de sintomas graves causados pela infecção do vírus que até o presente momento mata.

Um professor-pesquisador de Filosofia, cidadão brasileiro, que estuda a linguagem e o discurso não pode deixar de manifestar sob a perspectiva de uma ação ética do dizer: é 
Artigo do dossiê: De "gripezinha" e "resfriadinho" às incontáveis mortes pelo coronavírus: reflexões filosófico-linguísticas sobre a relação saúde-doença

fundamental realizar uma reflexão político-ideológica sobre qual mundo construímos e que relações com o outro (meu semelhante - igual a mim mesmo) estamos estabelecendo, porque neste momento em nossa história mundial somos conclamados a pensar sobre esse mal-estar.

Nós, pesquisadores das ciências humanas, não podemos fechar os nossos olhos para essa tragédia de uma morte anunciada que nos põe a ver Pejac, em sua obra, mostrando que somos vulneráveis, frágeis e, por causa dessa perecibilidade, precisamos, no combate a esse vírus tão devastador, levantar nossa voz e dizer: não é "gripezinha" e nem "resfriadinho", é uma doença que mata, que tira a vida, e nós não somos inumeráveis, temos identidade somos: Abadia, Abdon, Bráulio, Nicete Bruno, Aldir Blanc, Maria, Mário, Marco Antônio e ... milhares de brasileiros e brasileiras, de corpo atlético ou não, mortos por esse vírus.

\section{REFERÊNCIAS}

BAKHTIN, Mikhail Mikhailovich. Estética da criação verbal. 6. ed. Tradução de Paulo Bezerra. São Paulo: Martins Fontes, 2011.

BAKHTIN, Mikhail Mikhailovich. Por uma filosofia do ato responsável. Tradução São Paulo: Pedro e João Editores, 2012.

BAKHTIN, Mikhail Mikhailovich. Os gêneros do discurso. Tradução de Paulo Bezerra, São Paulo: Editora 34, 2016.

BAKHTIN, Mikhail Mikhailovich. Notas sobre literatura, cultura, e ciências humanas. Tradução de Paulo Bezerra, São Paulo: Editora 34, 2017.

BAKHTIN, Mikhail Mikhailovich. Teoria do romance I: a estilística. Tradução de Paulo Bezerra, São Paulo: Editora 34, 2015.

BRASIL, Secretaria de Comunicação. Pronunciamento do Presidente da República. Jornal do Brasil, Brasília. 24 mar. 2020. 1 vídeo (4:58 min). Disponível em:

https://www.youtube.com/watch?v=9TaHaCbbvSA\&feature=youtu.be. Acesso em: 17 fev. 2021.

BRITO, Robson Figueiredo. Um estudo da construção de posicionamentos identitários assumidos por estudantes pibidianos em relatos orais sobre a temática do tornar-se professor. 2016. Dissertação (Mestrado em Letras) Programa de Pós-graduação em Letras, PUC Minas, Belo Horizonte, 2016.

BRITO, Robson Figueiredo. Posicionamentos discursivos e identitários de sujeitos universitários em experiência de letramento acadêmico em um curso de Direito. 2019. Tese (Doutorado em Letras) - Programa de Pós-graduação em Letras, PUC Minas, Belo Horizonte, 2019. 
CRUZ, Marli Marques. Concepção de saúde-doença e o cuidado em saúde. Programa de Educação a distância da ENSP Fiocruz, Rio de Janeiro, 2012.

FARACO, Carlos Alberto Faraco. Linguagem e diálogo: as ideias linguísticas do círculo de Bakhtin. São Paulo: Parábola, 2009.

FOUCAULT, Michel. A ordem do discurso: aula inaugural no Collège de France pronunciada em 2 de dezembro de 1970. Tradução de Laura Fraga de Almeida Sampaio. São Paulo: Loyola, 2007.

GERALDI, João Wanderley. Leitura: uma oferta de contrapalavras. Educar, Curitiba, Editora UFPR, n. 20, p. 77-85. 2002.

MAINGUENEAU, Dominique. Cenas da enunciação. Organização de Sírio Possenti e Maria Cecília Pérez de Souza-e-Silva. Curitiba: Criar Edições, 2008a.

MAINGUENEAU, Dominique. Gênese dos discursos. Tradução de Sírio Possenti, São Paulo: Parábola, 2008b.

MARI, Hugo. Os lugares do sentido. Campinas: Mercado das Letras, 2008.

MONTILLA, Dalia Elena Romero. Noções básicas da epidemiologia. Fundação Oswaldo Cruz. Escola Nacional de Saúde Pública Sergio Arouca. Educação a Distância Envelhecimento e Saúde da Pessoa Idosa. / Fundação Oswaldo Cruz. Escola Nacional de Saúde Pública Sergio Arouca. Educação a Distância; organizado por Ana Paula Abreu Borges e Angela Maria Castilho Coimbra. - Rio de Janeiro: EAD/ENSP, 2008.

ORGANIZAÇÃO PAN-AMERICANA DE SAÚDE. Folha informativa COVID-19: Escritório da OPAS e da OMS no Brasil. 2020a. Atualizado em 25 de agosto 2020..Disponível em:

https://www.paho.org/bra/index.php?option=com_content\&view=article\&id=6101:covid19\&I temid=875\#risco. Acesso em: 11 fev. 2021.

ORGANIZAÇÃO PAN-AMERICANA DE SAÚDE. OMS afirma que covid-19 é agora caracterizada como pandemia. 2020b. Disponível em:

https://www.paho.org/bra/index.php?option=com_content\&view=article\&id=6120:omsafirma-que-covid-19-e-agora-caracterizada-como-pandemia\&Itemid=812. Acesso em: 18 fev. 2021.

ORLANDI, Eni Pulcinelli. A linguagem e seu funcionamento: as formas do discurso. Campinas, SP: Pontes, 2004.

ORLANDI, Eni Pulcinelli. Análise do discurso: princípios e procedimentos. 6. ed. São Paulo: Pontes, 2007.

ORLANDI, Eni Puccinelli. Discurso em análise: sujeito, sentido, ideologia. Campinas, SP: Pontes, 2012.

ORLANDI, Eni Puccinelli. As formas do silêncio. Campinas, SP: Ed. Unicamp, 2015.

Sapere aude - Belo Horizonte, v. 12 - n. 23, p. 66-86, Jan./Jun. 2021 - ISSN: 2177-6342 
Artigo do dossiê: De "gripezinha" e "resfriadinho" às incontáveis mortes pelo coronavírus: reflexões filosófico-linguísticas sobre a relação saúde-doença

PÊCHEUX, Michel. O discurso: estrutura ou acontecimento? Tradução de Eni Puccinelli Orlandi. Campinas, SP: Pontes, 1990.

PEJAC crea tres murales en el Hospital Valdecilla en reconocimiento a los sanitários. 2020. 1 vídeo (1:26 min). Disponível em: https://www.youtube.com/watch?v=eVU5i541Jy4. Acesso em: 18 fev. 2021.

POSSENTI, Sírio. Os limites do discurso: ensaios sobre discurso e sujeito. São Paulo: Parábola Editorial, 2009.

SONTAG, Susan. A doença como metáfora. São Paulo: Companhia das Letras, 2007.

TFOUNI, Leda Verdiani; PEREIRA, Anderson de Carvalho. Análise indiciária: uma topologia das singularidades. In: TFOUNI, Leda Verdiani; PEREIRA, Anderson de Carvalho; MILANEZ, Nilton (org.). O paradigma indiciário e as modalidades de decifração nas ciências humanas. São Carlos, SP: EDUFSCar, 2018. p. 121-148.

VOLÓCHINOV, Valentin. Marxismo e filosofia da linguagem: problemas fundamentais do método sociológico da linguagem. Tradução de Sheila Grillo. São Paulo: Editora 34, 2017.

VOLÓCHINOV, Valentin. A palavra na vida e a palavra na poesia: ensaios, artigos, resenhas e poemas. Organização de Sheila Grillo e Ekaterina Vólkova Américo. São Paulo: Editora 34, 2019. 